\title{
NOZZLE-DIFFUSER BASED MICRO BUBBLE PUMP
}

\author{
Jr-Hung Tsai and Liwei Lin* \\ Mechanical Engineering and Applied Mechanics, University of Michigan \\ *Mechanical Engineering, University of California at Berkeley \\ Mechanical Engineering, 5126 Etcheverry Hall, University of California, Berkeley, CA 94720-1740. \\ Email: ihtsai@engin.umich.edu Phone:(510) 642-8983 Fax: (510)643-5599
}

\begin{abstract}
A valve-less micropump is demonstrated by utilizing thermal bubbles as the actuation mechanism and a nozzle-diffuser pair as the flow controller. The pump consists of a single resistive heater, a pair of nozzle-diffuser flow controller, and a $1 \mathrm{~mm}$ in diameter, $45 \mu \mathrm{m}$ in depth pumping chamber. Liquid is pumped by generating and collapsing of thermal bubbles via resistive heating. A maximum flow rate of $5 \mu \mathrm{l} / \mathrm{min}$ is measured at the driving voltage of $20 \mathrm{~V}$ with $10 \%$ in duty at $250 \mathrm{~Hz}$ of pulsed power supply.
\end{abstract}

\section{INTRODUCTION}

Micro pumps have wide applications for handling small and precise fluid volumes on chemical, medical, and biomedical devices. Various types of micro pumps have been proposed and demonstrated over the last decade. They can be classified into following types based on the actuation mechanisms: mechanical displacement [1-3], bubble [4], electrohydrodynamic [5], and electrocapillarity [6] pumps. Among them, bubble pumps are less limited by the geometry and size than rotary and diaphragm pumps, also less constrained by the fluid type than electrohydrodynamic and electrocapillarity pumps.

One the other hand, micro valve has been a significant issue in all micropumps because of the relatively high leakage rate [710]. Previously, a valve-less pump has been demonstrated with a nozzle-diffuser type flow controller [4] and a diaphragm shape piezoelectric actuator as the pumping mechanism. In this work, in stead, bubbles function as a membrane in a diaphragm typed positive displacement pump. Together with the nozzle-diffuser design, this new pump provides advantages of flexible membrane, less dead volume in the pumping chamber and valve-less pumping.

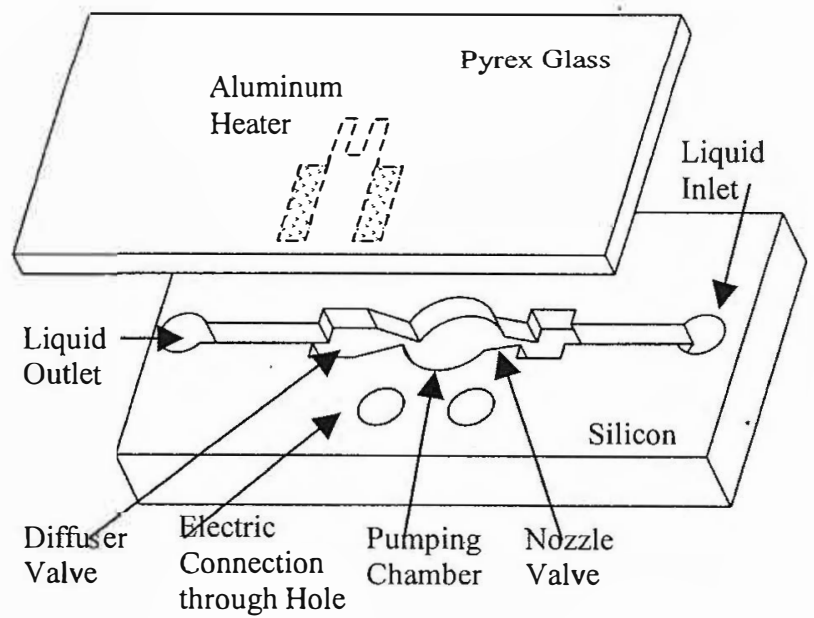

Fig. 1, Schematic drawing of the nozzle-diffuser based bubble pump.

\section{DEVICE FABRICATION}

The micropump is schematically drawn in Fig. 1. All the pumping chamber, nozzle-diffuser and channels are fabricated on a silicon substrate at the same depth of $45 \mu \mathrm{m}$. The meander aluminum heater on a Pyrex glass wafer is $10 \mu \mathrm{m}$ in width and $1 \mu \mathrm{m}$ in thickness. The circular pumping chamber is $1 \mathrm{~mm}$ in diameter and is connected with a pair of nozzle-diffuser flow controller of $30 \mu \mathrm{m}$ in the narrow neck, $274 \mu \mathrm{m}$ in the open mouth and $7^{\circ}$ in the diverge angle. The fluid channel is $200 \mu \mathrm{m}$ in width. Liquid and electricity connections are constructed by through holes on the silicon substrate. Figure 2 shows the simplified fabrication process flow and the fabricated device. On the silicon substrate, the surface is firstly grown a $1 \mu \mathrm{m}$ thick silicon dioxide layer, patterned and etched as the mask of pumping chamber, nozzle-diffuser and channels. A $9 \mu \mathrm{m}$ thick photoresist is spun on, patterned and etched by DRIE to open the liquid and electricity interconnection through holes. Afterwards, the photoresist is removed and the silicon wafer is put into DRIE etcher again to define the pumping chamber, valves and channels. After these steps, the silicon wafer is dipped into hydrofluoric acid (HF) to remove silicon dioxide. On the Pyrex glass, the wafer is patterned and etched in buffered HF to form shallow trenches for embedding the aluminum heater for the anodic bonding process. The aluminum layer is then evaporated and patterned by the lift-off process. The silicon and Pyrex wafers are finally aligned and anodically bonded at $380^{\circ} \mathrm{C}$.

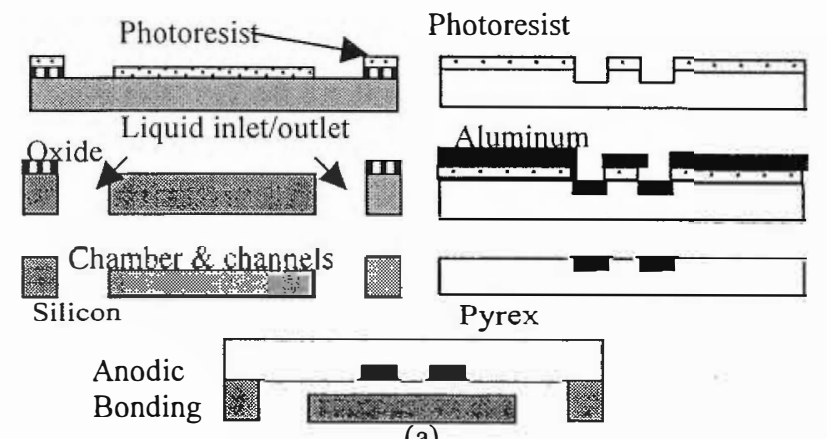

(a)

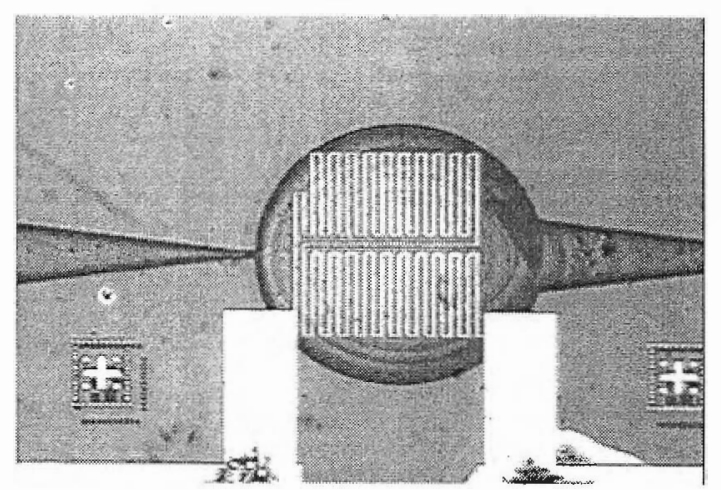

(b)

Fig. 2, (a) Simplified fabrication process flow. (b) Optical photograph of the fabricated micropump. 


\section{EXPERIMENTS}

The pumping flow rate is measured under the same inlet and outlet static pressures. For flow rate measurement, the fabricated micro pump is connected from the inlet and outlet holes to two polyimide tubes of $310 \mu \mathrm{m}$ in outer diameter and $275 \mu \mathrm{m}$ in inner diameter. The far ends of the tubes are then connected to syringes filled with liquid as liquid reservoirs. Once the equilibrium state is reached, the pumping flow rate is measured from the averaged speed of the air slug in the tubes.

Figure 3 shows the measured flow rates at three different pulse duties, $5 \%, 10 \%$ and $15 \%$, under pulse voltage of 20 volts. It is found that the maximum pumping rate is $5 \mu \mathrm{l} / \mathrm{min}$ when the pulse duty is at $10 \%$ and the pulse frequency at $250 \mathrm{~Hz}$. The pumping effect seems to diminish when pulse frequency is higher than $500 \mathrm{~Hz}$. The experiments of pumping rate with respect to pulse width have also been conducted as shown in Fig. 4. The maximum flow rates are found around the pulse width of 0.4 milliseconds at each pulse duties. In experiments, pumping chamber may saturate with gas if the pulse frequencies are outside the peak flow rate region. This gas saturation phenomenon is caused by improper ratio of heating to cooling cycles. Heat residual accumulates on the Pyrex substrate such that generated bubbles cannot condense back to liquid. Consequently, the oscillatory membrane-like pumping effect decreases. On the other hand, if two sequential heating periods are too close, the bubble has no sufficient time to collapse thoroughly. Once the pumping chamber is filled with bubbles, the pumping effect diminishes.

\section{SUMMARY}

In the paper, a micro nozzle-diffuser based bubble pump driven by pulse is demonstrated. The pumping volume flow rate is in the order few $\mu \mathrm{l} / \mathrm{min}$. Pulse duty control method is found more effective on the volume flow rate than the pulse frequency control method. Maximum volume flow rate at $5 \mu \mathrm{l} / \mathrm{min}$ is measured under the conditions of pulse duty at $10 \%$ and pulse frequency at $250 \mathrm{~Hz}$.

\section{FUTURE WORKS}

Although gas saturation can totally hinder the pumping effect, it can be improved and may be prevented by better thermal

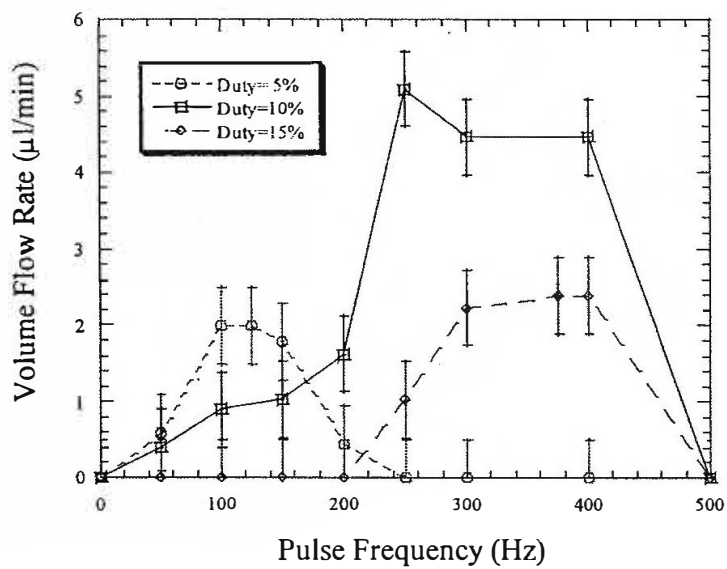

Fig. 3, Volume flow rate measured under the same inlet and outlet static pressure at pulse voltage of $20 \mathrm{~V}$.

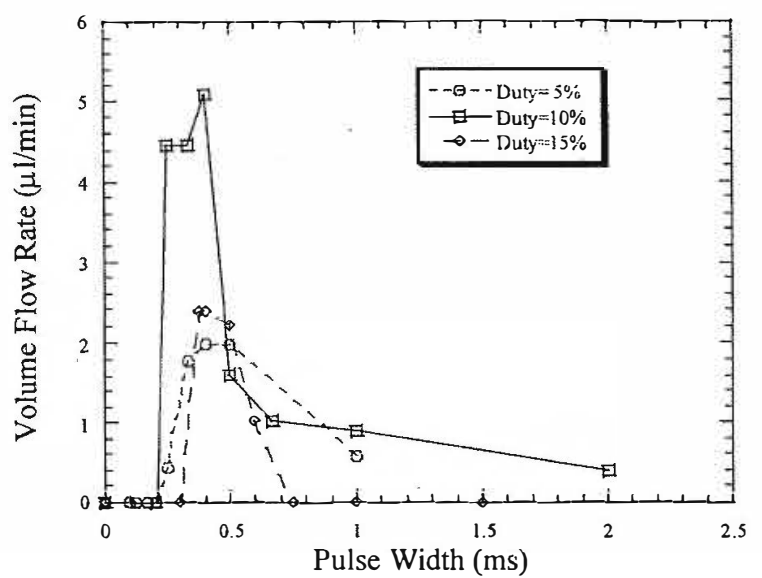

Fig. 4, Volume flow rate versus pulse width at pulse voltage of $20 \mathrm{~V}$.

management, such as operating the heater at higher temperature to generate more consistent bubbles, shortening the heating time to prevent heat accumulation on the Pyrex substrate, and widening the heater to generate larger bubble in shorter time. Once the thermal management is improved, the nozzle-diffuser based bubble pump can operate in a more efficient way,

\section{ACKNOWLEDGEMENTS}

The authors would thank the Professor Liepmann's research group at UC-Berkeley for the help on testing and discussions.

\section{REFERENCES}

1. H. Mizoguchi, M. Ando, T. Mizuno, T. Takagi and N. Nakajima, "Design and Fabrication of Light Driven Micropump," Proceedings of 1992 IEEE Micro Electro Mechanical Systems Workshop, Travemunde, Germany, 1992, pp. 31-36.

2. E. Stemme and G. Stemme, "A Vavleless Diffuser/Nozzle-based Fluid Pump," Sensors and Actuators, Vol. A39, 1993, pp. 159-167.

3. B. Bustgens, W. Bacher, W. Menz and W.K. Schomburg, "Micropump Manufactured by Thermoplastic Molding," Proceedings of 1994 IEEE Micro Electro Mechanical Systems Workshop, Oiso, Japan, 1994, pp. 18-21.

4. T. Jun and C.J. Kim, "Microscale Pumping with Traversing Bubbles in Microchannels," IEEE Solid-State Sensor and Actuator Workshop, Hilton Head Island, SC, 1996, pp. 144-147.

5. S.F. Bart, L.S. Tavrow, M. Mehregany and J.H. Lang, "Microfabricated Electrohydrodynamic Pumps," Sensors and Actuators, Vol. A21-23, 1990, pp. 193-197.

6. J. Lee and C.J. Kim, "Liquid Micromotor Driven by Continuous Electrowetting," Proceedings of 1998 IEEE Micro Electro Mechanical Systems Workshop, Heidelberg, Germany, 1998, pp. 538-543.

7. M. Esashi, S. Shoji and A. Nakano, "Normally Closed Microvalve and Micropump Fabricated on a Silicon Wafer," Sensors and Actuators, Vol. A20, 1989, pp. 163-169.

8. E.T. Carlen and C.H. Mastrangelo, "Simple, High Actuation Power, Thermally Activated Paraffin Microactuator," Intl. Conf. On Solid-State Sensors and Actuators (Transducers 99), Japan, 1999, pp. 9. S. Matsumoto, A. Klein and R. Maeda, "Development of Bidirectional Valve-less Micropump for Liquid," Proceedings of 1999 IEEE Micro Electro Mechanical Systems Workshop, Orlando, USA, 1999, pp. 141-146.

10. F. Forster, R.L. Bardell, M.A. Afromowitz, N.R. Sharma and A. Blanchard, "Design, Fabrication and Testing of Fixed-Valve Micropumps," Proceedings of the ASME Fluids Engineering Division, 1995, pp. 39-44. 